\title{
Medical Complications of Tattoos
}

\author{
(1) Selami Aykut Temiz¹, (1) Emin Özlü²
}

${ }^{1}$ Konya Eregli State Hospital, Clinic of Dermatology, Konya, Turkey

2Duzce University Faculty of Medicine, Department of Dermatology, Duzce, Turkey

\section{ABSTRACT}

Decorative tattooing involves the process of inserting external pigments and/or dyes into the dermis to create a permanent design. Tattooing is an application that has been widely practiced worldwide since ancient times. The popularity of permanent decorative skin tattooing has increased over the past thirty years. It will increase in patients with tattoo complications who apply to dermatologists due to the increase tattooing. Although tattooing is mostly for entertainment purposes, it can also be used for aesthetic and medical purposes. Although complications have decreased in modern, professional tattoos, these tattoing procedures may be associated with a wide variety of cutaneous and extracutaneous complications. Herein, we review the complications that can occur after tattooing, based on a comprehensive review of the literature. This review ensures an overview of the current aspects of medical complications associated with permanent tattooing based on previous reviews, studies, case series and related case reports.

Keywords: Tattoo, Complication, Adverse reaction, Pigment, Cancer

\section{Introduction}

Decorative tattooing involves the process of inserting external pigments and/or dyes into the dermis to create a permanent design [1]. Tattooing is an application that has been widely practiced worldwide since ancient times. The popularity of permanent decorative skin tattooing has increased over the past thirty years. In Western countries, $10 \%$ of the general population has skin tattoos, while $25 \%$ between the ages of $18-50$ have tattoos [1]. It will increase in patients with tattoo complications who apply to dermatologists due to the increase tattooing.

Although tattooing is mostly for entertainment purposes, it can also be used for cosmetic purposes (permanent eyebrows in alopecia areata, etc.). Some tattoo applications for aesthetic and therapeutic purposes (medical) are given in Table 1. Tattooing is done by inserting pigments and dyes into the dermis [2]. Tattoo inks have changed in recent years, with metal salts that were previously used frequently, replaced by azo pigments, an industrial pigment [3]. Azo pigments are preferred because of their more vivid colors and longevity. Although cutaneous reaction is less common in azo pigments, the long-term safety of these pigments is largely unknown. Møller and Wallin [4] evaluated azo pigments as genotoxic and carcinogenic.

The modern professional permanent tattoo process typically involves repeated injection of ink into the dermis using an electrically powered tattoo machine that can pierce the skin 3,000 times per minute. In professional tattoo parlors, items that come into contact with customers and potentially contaminate are usually disposable or autoclaved before each use [3]. Although complications have decreased in modern, professional tattoos, these tattooing procedures may be associated with a wide variety of cutaneous and extracutaneous complications [5].

In this review, we examined the cutaneous and systemic complications of tattooing (although they may intertwine from time to time, for example malignant melanoma (MM) can be classified as both a cutaneous and systemic complication) separately. 


\section{Cutaneous Complications of Tattooing}

The frequency of cutaneous complications related to tattooing is not clearly known. There are studies reporting the prevalence of complications between $2 \%$ and $43 \%[6,7,8]$. In a survey conducted with tattooed people, it was found that $42.6 \%$ complained about their tattoos. The three most common of these complaints are; wax and waning swelling (57\%), transient itching (45.7\%) and swelling after sun exposure (23\%) [8]. However, it may not be the right approach to evaluate all these complaints as pathological. We think the same that this type of cutaneous complaints should not be considered as a complication since it is an expected side effect in many tattoos.

There is no single classification of post-tattoo cutaneous complications and they have been classified in various ways in the literature. For example, they can be classified according to their clinical pathology (infection, hypersensitivity, etc.) as well as acute and chronic reactions [1]. In this review, we tried to classify cutaneous reactions according to their clinical types. In Table 2, we classified all post-tattoo cutaneous reactions in the literature.

\section{Pyogenic Cutaneous Infections}

Local disinfectants are generally not applied during tattooing, so failure to follow asepsis rules during or after the tattoo session increases the risk of infection [1]. After tattooing, acute superficial and deep pyogenic infections (folliculitis, acne varioliformis, impetigo, furunculosis, ecthyma, erysipelas, cellulitis, etc.) may occur [9]. Cutaneous pyogenic infections generally develop in association with Staphylococcus aureus, Streptococcus pyogenes, Corynebacterium, Pseudomonas, Clostridium and Klebsiella can be detected as causative agents. Such complications can be reduced with hygiene measures and modern aseptic tattooing techniques. However, tattooing procedures that do not comply with hygiene and asepsis rules can lead to dramatic consequences that can progress to deep cutaneous abscesses and necrotizing fasciitis [9]. Cutaneous pyogenic infections usually develop within days to weeks after the tattooing procedure. The management of post-tattoo pyogenic infections is not different from any other pyogenic infections.

Although serious and deep cutaneous infections have decreased significantly with modern tattooing methods, several serious cases of polybacterial cellulitis, necrotizing fasciitis and septicemia have recently been reported from New Zealand [10]. It is observed that such serious infections are generally not complied with the acepsis conditions and especially in traditional tattooing. Immunosuppressive patients are more inclined to such serious cutaneous infections. Tendas et al. [11] reported the fatal case of a 26-year-old man with a history of acute myeloid leukemia developing a large skin ulcer after tattooing. Before the tattooing procedure, the medical and drug history of the patients must be questioned.

\section{Viral Cutaneous Infections}

Viral contamination during tattooing is thought to be due to the presence of viral pathogens in the tattoo ink and tattoo needle [12]. Cutaneous viral infections due to human papilloma virus, herpes simplex virus and pox virus (molloscum contaginosum etc.) have been reported association with tattooing $[2,12]$.

\section{Fungal Cutaneous Infections}

Fungal contamination during tattooing is thought to be due to the presence of fungal pathogens in the tattoo needle. Cases of superficial tinea infection infected with trichophyton rubrum and epidermophyton floccosum have been reported association with tattooing $[2,13]$. It has also been defined as a tattoo complication in a case of zygomycosis, which is a rare mycotic infection [14].

Table 1. Tattoo applications for aesthetic and therapeutic purposes (medical)

\begin{tabular}{|l|l|}
\hline Medical situations & The purpose of tattoo usage \\
\hline Patients receiving cancer radiotherapy & It can be used to properly align the radiotherapy treatment areas \\
\hline Patients undergoing endoscopic surgery & $\begin{array}{l}\text { It can be used to mark surgical intervention areas in patients before } \\
\text { endoscopic gastrointestinal surgery }\end{array}$ \\
\hline Tattooing for medical alert purposes & $\begin{array}{l}\text { - Diabetic patients using insulin } \\
\text { - Patients with allergies and anaphylaxis } \\
\text { - Patients with Alzheimer's disease }\end{array}$ \\
\hline Patients with corneal pathology & It can be used for monitoring corneal pathology \\
\hline Patients with reconstructive breast surgery & $\begin{array}{l}\text { It can be used three-dimensional tattooing of the areola and nipple after } \\
\text { surgery }\end{array}$ \\
\hline Patients with alopecia & $\begin{array}{l}\text { It can be used to camouflage the areas with hair loss (especially } \\
\text { eyebrows) }\end{array}$ \\
\hline Patients with vitiligo & It can be used to camouflage areas with pigment loss \\
\hline Patients with hemangioma, Klippel-trenaunay or weber syndrome & It can be used to camouflage areas with vascular pathology \\
\hline
\end{tabular}




\section{Mycobacterial Cutaneous Infections}

Mycobacterial agents are common in nature and are highly resistant to disinfection methods [15]. Tattoo ink is a usual suspect in terms of growth and contamination of mycobacterial infectious agents [3]. Cases of cutaneous tuberculosis (tuberculosis verrucosa cutis, primary inoculation tuberculosis, lupus vulgaris, scrofuloderma), atypical mycobacterial infections and leprosy have been reported association with tattooing in the literature $[3,15,16,17,18]$.

Table 2. The post-tattoo cutaneous complications

\begin{tabular}{|c|c|}
\hline $\begin{array}{l}\text { Cutaneous } \\
\text { infections }\end{array}$ & $\begin{array}{l}\text { Pyogenic infections } \\
\text { - Impetigo contagiosa } \\
\text { - Acne varioliformis } \\
\text { - Ecthyma } \\
\text { - Erysipelas } \\
\text { - Cellulitis } \\
\text { Viral infections } \\
\text { - Verruca vulgaris } \\
\text { - Herpes simplex virus infections } \\
\text { - Molluscumcontagiosum } \\
\text { Fungal infections } \\
\text { - Superficial tinea infections } \\
\text { - Zygomycosis } \\
\text { Mycobacterial infections } \\
\text { - Tuberculosis verrucosa cutis } \\
\text { - Atypical mycobacterial infections } \\
\text { - Primary inoculation tuberculosis } \\
\text { - Leprosy }\end{array}$ \\
\hline Allergic disorders & $\begin{array}{l}\text { Allergic dermatitis } \\
\text { Urticaria } \\
\text { Photoallergic reaction }\end{array}$ \\
\hline Granulomas & $\begin{array}{l}\text { Sarcoid granulomas } \\
\text { Allergic granulomatous reactions } \\
\text { Keloid scars } \\
\text { Foreign body granulomas }\end{array}$ \\
\hline $\begin{array}{l}\text { Skin disease } \\
\text { localized in } \\
\text { tattooed area }\end{array}$ & $\begin{array}{l}\text { Psoriasis } \\
\text { Vitiligo } \\
\text { Lichen planus, lichen planus pemphigoides } \\
\text { Pseudolymphoma } \\
\text { Atopic dermatitis } \\
\text { Pyoderma gangrenosum } \\
\text { Darier's disease } \\
\text { Perforating dermatosis } \\
\text { Eruptive xanthomas } \\
\text { Granuloma annulare } \\
\text { Necrobiosis lipoidica } \\
\text { Miliums } \\
\text { Epidermoid cysts } \\
\text { Lichen sclerosus } \\
\text { Morphea } \\
\text { Discoid lupus erythematosus }\end{array}$ \\
\hline Neoplasms & $\begin{array}{l}\text { Basal cell carcinoma } \\
\text { Squamous cell carcinoma } \\
\text { Melanoma } \\
\text { Dermatofibroma } \\
\text { Dermatofibrosarcoma protuberans } \\
\text { Pseudoepitheliomatous hyperplasia }\end{array}$ \\
\hline
\end{tabular}

\section{Allergic Disorders}

Hypersensitivity reactions (or allergies) to tattoo inks are the most common complications after tattooing. In addition, it is often not possible to predict and prevent these complications [5]. The biggest fear of permanent tattooing is these unpredictable allergic reactions.

\section{Allergic Dermatitis}

After tattooing, the type 1 allergic reactions and anaphylaxis are very rare [19]. Usually a type 4 (delayed type) allergic reaction develops [20]. In post-tattoo care, moisturizers and dexpanthenol are often used, such as wound care [21]. Any topical agent used in post-tattoo care can cause allergic contact dermatitis [22]. Localized hypertrichosis has also been observed in some cases following this contact dermatitis in the literature [23].

\section{Urticaria}

Urticarial reactions can be triggered, especially by rubbing the blue-black tattooed areas [24]. Isolated urticaria and urticariaangioedema cases after tattoo have been reported in the literature $[25,26]$.

\section{Photoallergic Reaction}

Tattoos with yellow pigment containing cadmium sulfide are blamed for photodermatoses. In addition, cadmium sulfide can be found in minimal amounts in tattoos containing red color [2].

\section{Granulomas}

Like other exogenous materials injected into the skin, tattoo pigments can be perceived as foreign bodies for the body and cause granulomatous reactions [27]. Foreign body and sarcoid type granulomatous tattoo reactions constitute the majority of cases [3]. A definitive diagnosis by punch skin biopsy and histopathological examination is important. Because, any granulomatous reaction can be indicative of the underlying idiopathic sarcoidosis [6].

\section{Sarcoid Granulomas}

Sarcoidosis is an autoinflammatory condition of unknown cause, characterized by non-caseating epithelioid granulomas that can involve the skin and internal organs [28]. Sarcoidal granulomas that can develop from scars (scar sarcoid) and can also arise secondary to foreign matter, including tattoos, have often been reported in the literature $[27,29]$. The relationship of sarcoidal reactions to tattoos is unique, with tattoo reactions typically presenting as papules, nodules or plaques that are usually confined to tattooed area [30]. The onset of skin lesions may develop weeks or even decades after tattooing, the red pigment being responsible most often [31]. Patients with pre-existing sarcoidosis should be advised to avoid tattooing. 


\section{Allergic Granulomatous Reactions}

Allergic granulomatosis responses are difficult to treat reactions to the dye pigment of the tattoo. The most risky color pigment for this reaction is red, while the safest color pigment is black [6].

\section{Keloid Scars}

Mild fibrosis is usually seen as a result of the trauma of the tattoo needle. Hypertrophic scar or keloid scar development may occur in individuals susceptible to tattoos. It is very difficult to predict this complication. This risk increases in areas such as the chest, shoulders and upper arms, and in tattoos with damaged needles or poor quality needles [32]. Nevertheless, this complication can occur in any application and any localization.

\section{Foreign Body Granulomas}

Foreign body granulomas are relatively common after tattooing and are characterized by pigment-laden foreign body-type giant cells. The first-line approach is a trial of superpotent topical steroids or intralesional corticosteroids. In most cases, the reaction can regress over time [33].

\section{Skin Disease Localized in Tattooed Area}

Dermatoses that can develop after tattooing are quite common [34]. In many skin diseases known to develop Koebner phenomenon (e.g. psoriasis, vitiligo and lichen planus etc.), post-tattoo activation and active disease development in the tattoo area can be observed [35]. Also, skin diseases with skin trauma in the etiology (e.g. pseudolymphoma, pyoderma gangrenosum, granuloma annulare, milium and epidermoid cyst etc.) can also develop after tattooing.

In the literature, psoriasis, vitiligo, lichen planus, pseudolymphoma, atopic dermatitis, pyoderma gangrenosum, Darier's disease, perforating dermatosis, eruptive xanthoma, granuloma annulare, necrobiosis lipoidica, milium, epidermoid cyst, lichen sclerosus, morphea and discoid lupus erythematosus has been reported as post-tattto skin diseases $[2,5,6,34,35,36,37,38]$. Patients with a history of skin disease in their medical and family history should be informed that their illness may flare before getting the tattooing. Management of skin diseases on tattoos does not differ from nontattoo skin.

Laser epilation on tattooed areas requires special attention. Much more laser burns and keloids may develop in laser hair removal procedures performed on tattooed skin than normal skin [6].

\section{Neoplasms}

The relationship between tattoo and skin malignancies is controversy. Some authors argue that this relationship is accidental, while others draw attention to the potential carcinogenic effect of tattoo ink and argue that this relationship is not accidental [3]. When the literature is reviewed, there are many patient reports developing post-tattoo basal cell carcinoma (BCC), squamous cell carcinoma (SCC) and MM $[2,3,4,5,6]$. Again in reports; while BCC and MM have been reported to develop more frequently in black, dark blue or dark tattoos; SCC, keratoacanthoma and benign pseudoepitheliomatous hyperplasia have been reported to develop more frequently in red tattoos $[2,3,5,6,39]$.

The relationship between tattoo and MM is of particular importance due to the mixing of pigmented lesions. MM cases occurring after tattooing have been reported in many times. In addition, tattooing causes difficulties in the diagnosis and treatment of MM. Tattooing complicates the clinical and dermatoscopic examination of melanocytic nevi [40]. Patients with multiple melanocytic lesions should be advised to avoid tattooing, especially patients with melanoma risk factors. Tattoo artists should be informed about patients with multiple nevi, and these patients should definitely meet with their dermatologists before tattooing.

In addition to all these negativities in melanocytic nevi, tattoos can also cause negativities in patients who have already developed melanoma. Pigment-loaded macrophages caused by tattoo pigment can be confused with metastatic melanoma in the evaluation of sentinel lymph nodes and cause unnecessary radical lymph node dissection [41].

\section{Systemic Complications of Tattooing}

It is not always possible to divide tattoo complications into cutaneous and systemic with a sharp margin [6]. Some complications may start cutaneous and become systemic. In the literature, all systemic complications reported after tattooing are shown in Table 3. In this

Table 3. The post-tattoo systemic complications

\begin{tabular}{|l|l|}
\hline \multirow{2}{*}{ Systemic infections } & Syphilis \\
& Leprosy \\
Tetanus \\
Tuberculosis \\
Leishmaniasis \\
Endocarditis \\
Sepsis \\
Hepatitis B, C \\
AlDS
\end{tabular}


part, we will only evaluate isolated systemic complications (we will not repeat what we have examined in cutaneous complications here).

In the literature, there are reported cases syphilis, leprosy, tuberculosis, leishmaniasis, endocarditis, sepsis, hepatitis C, hepatitis B and AIDS (HIV) after tattooing [2,3,5,6,42]. These systemic infections are most frequently observed in conditions where asepsis rules are not followed, such as traditional tattoos. Today, if the rules of hygiene and asepsis are followed, the material is sterilized and needles are not shared between customers, the risk of developing these infections is considered to be absent [43]. Nevertheless, cases have been reported in which these infections can develop more easily and are fatal in immunocompromised individuals despite all these antisepsis rules [42].

Tattooing is more common among adolescents and psychological fluctuations are common in this period [44]. In some tattooed people, regret due to getting a tattoo can go up to internal stigma and depression over time [45]. In recent years, the interest of researchers in the psychogenic effects of tattoos has increased $[46,47,48]$.

Clinically detectable lymphadenopathies can be seen due to the migration of tattoo pigments to lymph nodes and is an expected side effect. However, due to the carcinogenic effects of tattoo inks, their contribution to the development of systemic lymphoma is controversial [49]. Prospective controlled clinical trials are required to enlighten the issue in terms of post-tattoo BCC, SCC, MM and systemic lymphoma development. Although these devastating side effects can often be controlled with treatment, they may require excision of the tattooed area and serious immunosuppressive treatments from time to time.

Rare complications such as uveitis and vasculitis have been reported after tattooing in the literature [50]. Although such systemic side effects are thought to be the result of sarcoidosis triggered after tattooing, it has been reported in the literature in cases who developed uveitis without sarcoidosis.

Also, complaints of burn in the tattoo areas have been reported in tattooed patients after magnetic resonance imaging (MRI) examination [6]. This situation is caused by the tattoo pigments being affected by the magnetic field. This risk is higher in large and dark pigment tattoos. In such risky patients, non-MRI imaging methods should be preferred, if possible.

\section{Conclusion}

Tattoos can be complicated by a diversity of infectious, inflammatory or neoplastic conditions. Over the years, complications have changed course with the development of dyes and methods used in tattooing. Cutaneous reactions are significantly reduced with the use of azo dyes in tattoo pigments instead of metal salts and the attention of tattoo artists to hygiene procedures. Hypersensitivity reactions (or allergies) to tattoo pigments are currently the most common complications in the tattooing. Unfortunately, it is not possible to predict and prevent these reactions. Again, the potential carcinogenic effects of azo dyes are not clearly known today. More clinical studies are needed to further clarify the complications of tattooing and to increase the knowledge.

It is important to raise more public awareness of tattooing and its complications. Especially tattoo artists need to be aware of tattoo complications and contraindications. Even the knowledge of which patient to refer to the clinician before tattooing can be vital for many complications. Patients with known skin diseases should definitely consult their dermatologist and get information about tattoo complications before tattooing. Patients with chronic conditions and/or impaired immunity should discuss with their physician about the complications of tattooing.

The management of tattoo complications must be done by a dermatologist. Treatment of tattoo-related complications is a specialized and experienced field that may include local destructive measures (dermabrasion, chemical destruction, cryotherapy, electro-surgery, ablative laser destruction), surgical excision, and thermolysis of the pigment using Q-switched laser therapy [51].

\section{Ethics}

Peer-review: Internally peer-reviewed.

\section{Authorship Contributions}

Surgical and Medical Practices: S.A.T., E.Ö., Concept: E.Ö., S.A.T., Design: E.Ö., S.A.T., Data Collection or Processing: S.A.T., E.Ö., Analysis or Interpretation: S.A.T., E.Ö., Literature Search: S.A.T., E.Ö., Writing: S.A.T., E.Ö.

Conflict of Interest: No conflict of interest was declared by the authors.

Financial Disclosure: The authors declared that this study received no financial support.

\section{References}

1. Kluger N. Acute complications of tattooing presenting in the ED. Am J Emerg Med 2012;30:2055-2063.

2. Kazandjieva J, Tsankov N. Tattoos: dermatological complications. Clin Dermatol 2007;25:375-382.

3. Simunovic C, Shinohara MM. Complications of decorative tattoos: recognition and management. Am J Clin Dermatol 2014;15:525-536.

4. Møller P, Wallin H. Genotoxic hazards of azo pigments and other colorants related to 1-phenylazo-2-hydroxynaphthalene. Mutat Res 2000;462:13-30.

5. Kluger N. An update on cutaneous complications of permanent tattooing Expert Rev Clin Immunol 2019;15:1135-1143. 
6. Kluger N. Cutaneous and systemic complications associated with tattooing. Presse Med 2016;45:567-576.

7. Høgsberg T, Hutton Carlsen K, Serup J. High prevalence of minor symptoms in tattoos among a young population tattooed with carbon black and organic pigments. J Eur Acad Dermatol Venereol 2013;27:846-852.

8. Kluger N. Self-reported tattoo reactions in a cohort of 448 French tattooists. Int J Dermatol 2016;55:764-768.

9. Kluger N. Complications infectieuses cutanées associées au tatouage permanent [Cutaneous infections related to permanent tattooing]. Med Mal Infect 2011;41:115-122.

10. Porter CJ, Simcock JW, MacKinnon CA. Necrotising fasciitis and cellulitis after traditional Samoan tattooing: case reports. J Infect 2005;50:149-152.

11. Tendas A, Niscola P, Barbati R, Abruzzese E, Cuppelli L, Giovannini M, Scaramucci L, Fratoni S, Ales M, Neri B, Morino L, Dentamaro T, De Fabritiis P. Tattoo related pyoderma/ectyma gangrenous as presenting feature of relapsed acute myeloid leukaemia: an exceptionally rare observation. Injury 2011;42:546-547.

12. Ragland HP, Hubbell C, Stewart KR, Nesbitt LT Jr. Verruca vulgaris inoculated during tattoo placement. Int J Dermatol 1994;33:796-797.

13. Brancaccio RR, Berstein M, Fisher AA, Shalita AR. Tinea in tattoos. Cutis 1981;28:541-542.

14. Parker C, Kaminski G, Hill D. Zygomycosis in a tattoo, caused by Saksenaea vasiformis. Australas J Dermatol 1986;27:107-111.

15. Drage LA, Ecker PM, Orenstein R, Phillips PK, Edson RS. An outbreak of Mycobacterium chelonae infections in tattoos. J Am Acad Dermatol 2010;62:501-506.

16. Kennedy BS, Bedard B, Younge M, Tuttle D, Ammerman E, Ricci J, Doniger AS, Escuyer VE, Mitchell K, Noble-Wang JA, O'Connell HA, Lanier WA, Katz LM, Betts RF, Mercurio MG, Scott GA, Lewis MA, Goldgeier MH. Outbreak of Mycobacterium chelonae infection associated with tattoo ink. N Engl J Med 2012;367:1020-1024.

17. Wong HW, Tay YK, Sim CS. Papular eruption on a tattoo: a case of primary inoculation tuberculosis. Australas J Dermatol 2005;46:84-87.

18. Ghorpade A. Inoculation (tattoo) leprosy: a report of 31 cases. J Eur Acad Dermatol Venereol 2002;16:494-499.

19. Hibler BP, Rossi AM. A case of delayed anaphylaxis after laser tattoo removal. JAAD Case Rep 2015;1:80-81.

20. Serup J, Carlsen KH, Sepehri M. Tattoo complaints and complications: diagnosis and clinical spectrum. Curr Probl Dermatol 2015;48:48-60.

21. Ayanlowo 00, Gold-Olufadi SA, Akinkugbe AO, Otrofanowei E, Nga CN, Olumide YM. Growing trend of tattooing and its complications in Nigeria. Int J Dermatol 2017;56:709-714.

22. Rogowska P, Szczerkowska-Dobosz A, Kaczorowska R, Słomka J, Nowicki R. Tattoos: Evaluation of knowledge about health complications and their prevention among students of Tricity universities. J Cosmet Dermatol 2018;17:27-32.

23. Ozcan D, Seckin D. A Case of Localized Hypertrichosis Due to Temporary Henna Tattoo. Turk J Dermatol 2014;3:164-165.

24. de Groot AC. Side-effects of henna and semi-permanent 'black henna'tattoos: a full review. COD 2013;69:1-25.

25. Gulen F, Zeyrek D, Altinoz S, Peker E, Demir E, Tanac R. Urticaria and angioneurotic edema due to the temporary henna tattoo. Minerva pediatrica 2006;58:583-585.

26. Onder M, Atahan CA, Oztas P, Oztaş MO. Temporary henna tattoo reactions in children. Int J Derm 2001;40:577-579.
27. Thum CK, Biswas A. Inflammatory complications related to tattooing: a histopathological approach based on pattern analysis. Am J Dermatopathol 2015;37:54-66.

28. Torquato MF, Costa MKSD, Nico MMS. Cutaneous sarcoidosis: clinicoepidemiological profile of 72 patients at a tertiary hospital in São Paulo, Brazil. An Bras Dermatol 2020;95:57-62.

29. Antonovich DD, Callen JP. Development of sarcoidosis in cosmetic tattoos. Arch Dermatol 2005;141:869-872.

30. Kluger N. Sarcoidosis on tattoos: a review of the literature from 1939 to 2011. Sarcoidosis Vasc Diffuse Lung Dis 2013;30:86-102.

31. Ito T, Fujita $Y$, Nishie $W$, Hirata $Y$, Shimizu H. Spontaneously resolving granulomatous tattoo reaction in multiple color regions. J Dermatol 2014;41:647-648.

32. Boulart L, Mimoun M, Noel W, Malca N, Chaouat M, Boccara D. Dealing with tattoos in plastic surgery. Complications and medical use. Ann Chir Plast Esthet 2017;62:23-29.

33. Kluger N, Hakimi S, Del Giudice P. Keloid occurring in a tattoo after laser hair removal. Acta Derm Venereol 2009;89:334-335.

34. Islam PS, Chang C, Selmi C, Generali E, Huntley A, Teuber SS, Gershwin ME. Medical Complications of Tattoos: A Comprehensive Review. Clin Rev Allergy Immunol 2016;50:273-286.

35. An İ. Tatuaj Komplikasyonu Olarak Tip 2 Köbner Fenomeni Gelișen Psoriasisli Bir Olgu. Dermatoz 2018;9:1-3.

36. Marchesi A, Parodi PC, Brioschi M, Marchesi M, Bruni B, Cangi MG, Vaienti L. Tattoo ink-related cutaneous pseudolymphoma: a rare but significant complication. Case report and review of the literature. Aesthetic Plastic Surg 2014;38:471-478.

37. Gao H, Chen J. Eruptive xanthomas presenting in tattoos. CMAJ 2015;187:356.

38. Lim A, Tang PY, Oh CC. Lichen planus pemphigoides after body tattooing. J Cosmet Dermatol 2020;19:3048-3052.

39. Foerster M, Schreiver I, Luch A, Schüz J. Tattoo inks and cancer. Cancer Epidemiol 2020;65:101655.

40. Caccavale S, Moscarella E, De Fata Salvatores G, Piccolo V, Russo T, Argenziano G. When a melanoma is uncovered by a tattoo. Int J Dermatol 2016;55:79-80.

41. Manganoni AM, Sereni E, Pata G, Ungari M, Pavoni L, Farisoglio C, CalzavaraPinton PG, Farfaglia R. Pigmentation of axillary sentinel nodes from extensive skin tattoo mimics metastatic melanoma: case report. Int J Dermatol 2014;53:773-776.

42. Shinohara MM. Complications of decorative tattoo. Clin Dermatol 2016;34:287-292.

43. Urbanus AT, Van Den Hoek A, Boonstra A, Van Houdt R, De Bruijn LJ, Heijman T, Coutinho RA, Prins M. People with multiple tattoos and/or piercings are not at increased risk for HBV or HCV in The Netherlands. PLoS One 2011;6:16.

44. Naudé L, Jordaan J, Bergh L. "My Body is My Journal, and My Tattoos are My Story": South African Psychology Students' Reflections on Tattoo Practices. Current Psychology 2019;38:177-186.

45. Broussard K, Harton H. Tattoo or taboo? Tattoo stigma and negative attitudes toward tattooed individuals. The Journal of social psychology 2017;158:521540 .

46. Pérez-Cotapos S ML, De Cuyper C, Cullen R (2018). Complications of Tattooing and Scarring. In: De Cuyper C., Pérez-Cotapos S M. (eds) Dermatologic Complications with Body Art. Springer, Cham. DOI: https://doi. org/10.1007/978-3-319-77098-7_4

47. Bhargava S, Singh R, Kumari K. Significance of tattoo marks in forensic psychology: a review. Int J Curr Adv Res 2016;5:857-859. 
48. Guéguen N. Effects of a tattoo on men's behavior and attitudes towards women: An experimental field study. Arch Sex Behav 2013;42:1517-1524.

49. Armiger WG, Caldwell EH. Primary lesion of a non-Hodgkin's lymphoma occurring in a skin tatoo: case report. Plast Reconstr Surg 1978;62:125-127.
50. Ostheimer TA, Burkholder BM, Leung TG, Butler NJ, Dunn JP, Thorne JE. Tattoo-associated uveitis. Am J Ophthalmol 2014;158:637-643.

51. Cannarozzo G, Negosanti F, Sannino M, Santoli M, Bennardo L, Banzola N, Negosanti L, Nisticò SP. Q-switched Nd:YAG laser for cosmetic tattoo removal. Dermatol Ther 2019;32:13042. 